\title{
Carvajal Villaplana, Álvaro (2014) Las convergencias entre ciencia, tecnología y desarrollo. San José, Costa Rica. Ediciones Guayacán. Revisado por Luis Camacho'.
}

\section{\begin{tabular}{l|l} 
Recibido 28/V/2015 & Aprobado 26/VI/2015
\end{tabular}}

El autor obtuvo su doctorado en la Universidad Carlos III de Madrid y su tesis versó sobre los discursos relacionados con ciencia, tecnología y desarrollo a lo largo de la historia de Costa Rica (Carvajal 2012). Actual Director del Programa de Posgrado de Filosofía en la Universidad de Costa Rica, esta obra-su más reciente en una serie de escritos sobre dicha tríada, a su vez parte de una producción más abarcadora-sitúa el análisis en un contexto más amplio, más allá de geografías o historias particulares.

La importancia del análisis de las conexiones entre los tres aspectos vistos como sistemas sociales se puede notar en sus consecuencias, pues de diferentes maneras de organizarlos se siguen resultados diferentes, con implicaciones en el grado de beneficio que aportan a la colectividad. Aunque en la Introducción el autor se muestra muy comprensivo e incluyente, queda claro pronto que siente poca simpatía por posiciones de holismo extremo, relativismo radical, discontinuidades variadas y constructivismo social. Se enfatiza con frecuencia en la complejidad de las relaciones entre tres realidades que tienen su propia dinámica; esta multidimensionalidad le da al libro un atractivo singular desde el comienzo. Otros dos elementos valiosos saltan a la vista enseguida: abundante bibliografía y detallado índice analítico.

La organización de la obra en tres capítulos responde a la originalidad de empezar por la tecnología por su carácter de mediación y al enfoque de introducir la ciencia y el desarrollo como una red de conexiones. La división en tres grandes capítulos tiene el mérito de incorporar progresivamente nuevos elementos de la realidad estudiada. Así, en el primer capítulo se ofrece una nueva mirada a la tecnología con énfasis en la continuidad. En el segundo se pasa del examen de las relaciones entre ciencia, tecnología y desarrollo a un análisis muy interesante sobre el cambio tecnológico. En el tercero el panorama se amplía con tres actores más: cultura, capacidades y políticas. Con esto la visión global queda completa: uno puede empezar por las políticas de promoción científica y tecnología de un país (v.g. la Ley \# 7169 de 1990 en Costa

\footnotetext{
${ }^{1}$ Presidente de la Asociación Costarricense de Filosofía, Profesor ad honorem de la Escuela de Filosofía, Universidad de Costa Rica. Correo electrónico: Icn20032003@yahoo.com.
} 
Rica) y preguntarse cuáles capacidades se requieren para que se cumplan sus metas, qué tipo de cultura la promueve y cuáles la desestimulan. Puesto que en cada uno de los capítulos los autores fundamentales son diferentes (v.g. Ladrière para el tema de la cultura; Amartya Sen para capacidades) el manejo adecuado de la literatura exige un esfuerzo notable. De allí la abundancia de la bibliografía, que el autor consigue utilizar sin cometer injusticias con los autores mencionados ni abrumar al lector.

Al argumentar sobre los diferentes puntos de vista, Carvajal prefiere en general las visiones más complejas sobre las más simples. Por ejemplo, al preguntarse cómo se relacionan la ciencia con la tecnología se critica la visión lineal según la cual la tecnología no es más que el resultado de la aplicación de la ciencia. Si así fuera, sería difícil entender por qué se dan conflictos constantes entre las instituciones de ciencias básicas y matemáticas-por un lado-y las tecnológicas, por otro. Tanto en la vida académica como en la profesional hay choques entre geólogos e ingenieros civiles, entre químicos e ingenieros químicos, entre biólogos y agrónomos, y así sucesivamente. Es frecuente que los estudiantes en áreas ingenieriles prefieran recibir clases de matemáticas y ciencias básicas con profesores de sus propias disciplinas versados en dichas materias en vez de matemáticos o científicos sin experiencia en las ingenierías. La queja habitual es que estos últimos no tienen en cuenta o no conocen lo que se requiere en el campo específico. Las diferencias institucionales no se limitan a diferencias culturales, pues aparecen en contextos variados. Los conflictos apuntan a historias separadas de las instituciones, más que de las sociedades que las albergan y revelan mucho acerca del origen y evolución de los actores.

Así como el análisis del cambio tecnológico unifica los temas del capítulo segundo, las políticas para la utilización de la ciencia y de la tecnología en programas de desarrollo constituyen el tema central del tercer capítulo. La recopilación de distintas posiciones en ambos casos procura hacer justicia a los diferentes puntos de vista; al final el lector queda con la impresión de que difícilmente se podría estructurar con más detalle un discurso que unifique tantas ideas.

Por otra parte, dada la enorme variedad de subtemas que abarca el libro es natural que el lector quede con ganas de un análisis más detallado de algunos de los puntos de vista tratados. En particular, las diferencias y semejanzas entre el constructivismo social en ciencias y en tecnología darían para consideraciones donde se rescaten algunas ideas interesantes del último. Por una parte, la idea de que la escogencia de una teoría científica sobre otras es simplemente preferencia social es incapaz de explicar la uniformidad de la aceptación de teorías en culturas diferentes, ni por qué algunas teorías han tenido una larga historia de tanteos, transformaciones y resurrecciones a pesar de la diversidad de sociedades que las han conocido. Si seguimos encontrando en los libros de mecánica las leyes de palancas de Arquímedes y su explicación de por qué algunos cuerpos flotan y otros no, tendríamos que concluir según los constructivistas 
sociales que la única diferencia entre Arquímedes y otros autores cuyas ideas sobre el movimiento han sido superadas (v.g. Descartes) es que el primero ha resultado aceptable a todas las sociedades desde hace milenios mientras otros no han tenido tanta suerte. Pero entonces nos podemos preguntar por qué ha sido así y no de otra manera, y el constructivismo social difícilmente tendría una respuesta convincente. Para quien esto escribe la respuesta es muy sencilla: si queremos lograr que un cuerpo flote nos resulta útil la explicación de Arquímedes mientras otras no.

Pero en tecnología el constructivismo social significa otra cosa y sus implicaciones son mucho menos relativistas que en las ciencias. El estudio de Pinch y Bijker (1989: 17-50) sobre la evolución de la bicicleta en relación con grupos sociales y sus problemas es un clásico que puede tomarse como modelo aplicable a otras tecnologías. Relacionar diseño de bicicletas con problemas de diferentes grupos sociales que las usan no tiene nada que ver con la negación de la realidad independiente del sujeto que conoce, pues tan objetivas son las partes materiales del vehículo como las preferencias subjetivas de los usuarios. Unas y otras pueden ser objeto de estudios estadísticos, explicaciones causales y predicciones. Obviamente entre dos tecnologías igualmente exitosas la escogencia social (empujada a veces por la propaganda comercial) suele ser determinante, por lo que en general se puede decir que los artefactos responden a preferencias sociales. Pero su éxito o fracaso no es simplemente cuestión de gustos; si así fuera no habría accidentes tecnológicos. A diferencia de la ciencia, en tecnología no se aceptan misterios ni ignorancia; de otro modo ni las garantías ni los seguros serían rentables. Los filósofos se pueden permitir el lujo de negar la existencia independiente de la realidad, la objetividad de la verdad y la importancia de la evidencia en apoyo de las teorías e hipótesis; para quienes tratan de resolver problemas angustiosos como la miseria y la enfermedad esas posiciones suenan a escapismo. La orientación general de la obra comentada se inserta en la tendencia de la reflexión filosófica en Costa Rica, más realista y menos idealista que en otras latitudes.

En el tercer capítulo el autor expone algunas de las maneras como se ha concebido el desarrollo y le dedica especial consideración a la teoría de Amartya Sen sobre capacidades (Sen 1999), que se ha convertido en la retórica habitual del discurso de organismos internacionales y componente obligado de documentos oficiales locales (v.g. Programa Estado de la Nación 2014: 23,26). Carvajal hábilmente conecta la noción de capacidades con la de cultura tecnológica, que tiene otro origen. Esto le permite distinguir en la cultura los aspectos que fomentan el desarrollo de los que se oponen a ella.

Aquí queremos aprovechar la oportunidad de señalar que el énfasis en capacidades lamentablemente ha dejado de lado la insistencia en la satisfacción de necesidades básicas como requisito fundamental para el desarrollo y tarea urgente en gran número de países. Otro efecto 
secundario y preocupante de dicha insistencia es el olvido de la idea de desarrollo sostenible, al que sin embargo se ha retornado en la formulación de los 17 objetivos fijados por la Asamblea General de las Naciones Unidas para 2030, como continuación de los 8 objetivos del milenio que se fijaron en 2002 como metas para el 2015 (Camacho 2015).

Si se considera la productividad del autor de Convergencias, nos atrevemos a predecir que estos temas serán objeto de futuras investigaciones tan provechosas como la que hemos reseñado aquí.

\section{Bibliografía}

Bijker, W.E-Hughes,T.P.-Pinch,T.J. (eds) (1989) The Social Construction of Technological Systems. New Directions in the Sociology and History of Technology. Cambridge, Mass. MIT Press.

Camacho, L.(2015) Sustainable development goals: kinds, connections and expectations, en Journal of Global Ethics. DOI: 10.1080/17449626.2015.1010097.

Carvajal, Á. (2012) Filosofía y discursos: la ciencia y la tecnología en el desarrollo de Costa Rica. San José, Costa Rica, Editorial Guayacán.

Ladrière, J.(1977) El reto de la racionalidad. La ciencia y la tecnología frente a las culturas. Salamanca, Sígueme/UNESCO.

Programa Estado de la Nación (2014) Estado de la Ciencia, la Tecnología y la Innovación. San José, Costa Rica, EDISA.

Sen, A. (1999) Desarrollo y libertad. Barcelona ,Planeta. 